\title{
Nanodisperse Hadfield (110G13L) Steel Modification
}

\author{
Vladimir A. Poluboyarov*a, Zoya A. Korotaeva \\ Alexander A. Zhdanok ${ }^{\mathrm{a}}$ and Victor A. Kuznetzov ${ }^{\mathrm{b}}$ \\ anstitute of Solid State Chemistry and Mechanochemistry \\ 18 Kutateladze Str., Novosibirsk, 630128, Russia \\ ${ }^{b}$ LTD "Sibelectroterm" \\ 51 Petukhov Str., Novosibirsk, 630088, Russia
}

Received 20.08.2015, received in revised form 16.10.2015, accepted 25.01.2016

Intramold Hadfield steel modification with different disperse modifiers containing boron, tungsten and titanium carbides, ferrotitanium and carbon as the active phase has been carried out. To improve the wettability, modifiers have been preliminary treated with copper powder in a planetary centrifugal mill. It has been revealed that the microstructure of steel samples produced contains austenite and carbides precipitating inside and along the grain boundaries. Considerable increase of tensile strength by 14.5, 18.0 and $9.0 \%$ is characteristic for steel samples treated with modifiers containing boron carbide (active phase concentration - $0.056 \%$ ), mixture of tungsten and titanium carbides $(0.033 \%)$ and titanium carbide $(0.083 \%)$, correspondingly. Besides, the application of the mixture of tungsten and titanium carbides has allowed improving percent elongation by $40 \%$. The application of modifiers containing boron carbide and mixture of tungsten and titanium carbides favours uniform distribution of carbides and considerable decrease of grain size; grain size (according State Standard 5639) corresponds to two points (actual medium grain diameter is 0.387-0.694 and 0.338-0.581 mm correspondingly). The size of test sample grain is more than three points (actual medium grain diameter is 2.325-3.168 $\mathrm{mm}$ ). Steel grain in the other modified samples corresponds to three and more points.

Keywords: grain size, tensile strength, disperse modification, tungsten, titanium and boron carbides, copper, mechanochemical treatment, modifier, elongation, SHS, Hadfield steel, ferrotitanium.

Citation: Poluboyarov V.A., Korotaeva Z.A., Zhdanok A.A., Kuznetzov V.A. Nanodisperse hadfield (110G13L) steel modification, J. Sib. Fed. Univ. Eng. technol., 2016, 9(1), 117-125. DOI: 10.17516/1999-494X-2016-9-1-117-125.

(C) Siberian Federal University. All rights reserved

* Corresponding author E-mail address: sanych@solid.nsc.ru 


\title{
Нанодисперсное модифицирование стали 110Г13Л
}

\author{
В.А. Полубояров ${ }^{\mathrm{a}}$, З.А. Коротаева ${ }^{\mathrm{a}}$, \\ А.А. Жданок ${ }^{\mathbf{a}}$ В.А. Кузнецов ${ }^{\tilde{\sigma}}$ \\ ${ }^{a}$ Институт химии твердого тела и механохимии СО РАН \\ Россия, 630128, Новосибирск, ул. Кутателадзе, 18 \\ ${ }^{\sigma} \mathrm{OOO}$ «Сибэлектротерм» \\ Россия, 630088, Новосибирск, ул. Петухова, 51
}

Проведено внутриформенное модифицирование стали 110Г13Л различными дисперсными модификаторами, содержащими в качестве активной фазы карбиды бора, вольфрама, титана, ферротитан, углерод. Для улучшения смачиваемости модификаторы были предварительно обработаны с порошком меди в планетарной центробежной мельнице. Выявлено, что микроструктура полученных образиов стали состоит из аустенита и карбидов, выделившихся внутри и по границам зерен. Значительное увеличение временного сопротивления разрыву на 14,5, 18,0 и 9,0 \% показали образиы стали, отработанные модификаторами, содержащими карбид бора (концентрачия активной фазы 0,056 \%), смесь карбидов вольфрама и титана (0,033\%) и карбид титана (0,083 \%) соответственно. Кроме того, применение смеси карбидов вольфрама и титана позволило увеличить относительное удлинение на 40 \%. Применение модификаторов, содержащих карбид бора и смесь карбидов вольфрама и титана, способствует равномерному распределению карбидов и значительному уменьшению размера зерна; величина зерна (по ГОСТ 5639) соответствует двум баллам (фактический средний диаметр зерна 0,3870,694 и 0,338-0,581 мм соответственно). Величина зерна контрольного образиа - более трех баллов (фактический средний диаметр зерна 2,325-3,168 мм). В остальных модифицированных образиах стали зерно соответствует трем баллам и более.

Ключевые слова: величина зерна, временное сопротивление разрыву, дисперсное модифицирование, карбиды вольфрама, титана и бора, медь, механохимическая обработка, модификатор, относительное удлинение, СВС, сталь 110Г13Л, ферротитан.

\section{Введение}

Дисперсное модифицирование металлов, сплавов, пластических масс к настоящему времени имеет под собой уже солидную теоретическую и экспериментальную базу. Однако на пути широкого практического использования лежат многочисленные трудности технологического характера. Как правило, способ их преодоления напрямую зависит от направления модифицирования, что требует каждый раз, руководствуясь общими принципами, ставить трудоемкие эксперименты по оптимизации процессов введения нанопорошков в матрицу, сообразуясь с их химической природой [1-4]. Механохимия может существенно облегчить путь к достижению положительного результата.

Современная литература, посвященная влиянию наноразмерных частиц тугоплавких фаз на структуру и механические свойства чугунов [5-11] и сталей $[1-3,10,12,13]$, весьма обширна. Комплексные исследования влияния различных дисперсных модификаторов и условий модифицирования на модельных системах (модифицирование чугуна в форме) были проведены в работах [14-16].

Установлено, что разработанные модификаторы эффективно воздействуют на процессы кристаллизации расплавов: меняют соотношение фаз (феррит/перлит), вплоть до полной заме- 
ны ферритной составляющей на перлитную, изменяют форму, длину и распределение графитовых включений. Обнаружено, что максимальная эффективность модификаторов проявляется при концентрации тугоплавких частиц в диапазоне 0,0015-0,05 \% по массе.

Предлагаемая технология не требует изменения существующих технологий, рецептура чугуна не меняется (нарушений требования ГОСТов и ТУ нет). Основная цель модифицирования - существенно изменить кристаллизацию жидкого металла за счет введения огромного количества центров кристаллизации, при этом структура металла в литом состоянии становится мелкокристаллической и значительно более однородной. За счет изменения структуры серьезно улучшаются механические и другие технологические свойства металла (например, коррозионная стойкость).

В данной работе исследовалось влияние различных дисперсных модификаторов на свойства стали 110Г13Л при внутриформенном модифицировании.

\section{Материалы и методы исследования}

Выплавка стали проводилась в печи ДС6-Н1 по технологии переплава легированных отходов (110Г13Л). Масса металла 5,5 т.

Раскисление стали на выпуске осуществляли путём подачи на дно разливочного ковша 8 кг специального раскислителя (70\% Al, $20 \% \mathrm{Fe}, 5 \% \mathrm{Ca}$, остальное - C, $\mathrm{Si}, \mathrm{Cu})$ с добавкой 5 кг гранулированного алюминия.

Температура стали на выпуске (в ковше) $1460{ }^{\circ} \mathrm{C}$.

Модифицирование металла проводилось в форме путём закладки модификатора в специальные реакционные камеры. Количество металла в форме 120 кг.

Было изготовлено семь опытных форм с реакционными камерами, куда были заложены следующие модификаторы в виде порошков:

1) углерод : медь $=1: 1(200$ г);

2) карбид бора : медь $=1: 2(200$ г);

3) ферротитан : медь $=1: 1(200$ г);

4) (смесь карбидов вольфрама и титана) : медь $=2: 5$ (140 г);

5) карбид титана : медь $=1: 1(200$ г);

6) (смесь ферротитана, карбида бора, углерода) : медь = 1:4 (300 г);

7) медь (100 г), контрольный образец.

Смесь карбидов вольфрама и титана (модификатор 4) была получена методом СВС по методике, описанной в [17]. Соотношение карбидов вольфрама (в пересчете на WC) и карбида титана в данном модификаторе составляло 75:25.

Модификаторы для улучшения смачиваемости расплавом металла предварительно были обработаны в планетарной центробежной мельнице в течение 1 мин.

После приработки стопора были залиты первыми все семь опытных форм.

Заливка протекала спокойно, без пироэффектов.

Во всех опытных формах были предусмотрены и залиты по две приливные пробы типа «топорик» для определения механических свойств и микроструктуры.

Кроме того, от каждой литниковой системы формы были вырезаны реакционные камеры для определения полноты срабатывания модификатора. 
Исследования микроструктуры образцов из стали 110Г13Л были проведены отделом металловедения и термической обработки технического управления ОАО «ЕВРАЗ ЗСМК».

Травление образцов проводили 4\%-ным спиртовым раствором $\mathrm{HNO}_{3}$.

Нумерация образцов сталей (1-7) соответствует нумерации образцов модификаторов (1-7).

\section{Результаты и обсуждение}

В табл. 1 приведен химический состав готовой стали.

Состав, количество модификаторов и результаты механических испытаний сталей, обработанных этими модификаторами, отражены в табл. 2.

Значительное увеличение временного сопротивления разрыву показали образцы стали, обработанные модификаторами 2, 4 и 5 (на 14,5, 18,0 и 9,0 \% соответственно). Кроме этого, применение модификатора 4 (смесь карбидов вольфрама и титана, концентрация активной фазы $0,033 \%$ ) позволило увеличить относительное удлинение на 40 \%. Свойства сталей, обработанных другими модификаторами, - в пределах контрольного образца 7.

Результаты микроструктурных исследований образцов стали представлены на рис. 1 и в табл. 3.

Было выявлено, что микроструктура образцов состоит из аустенита и карбидов, выделившихся внутри и по границам зерен (рис. 1).

Таблица 1. Химический состав стали

\begin{tabular}{|c|c|c|c|c|c|c|c|c|c|}
\hline Элементы & $\mathrm{C}$ & $\mathrm{Si}$ & $\mathrm{Mn}$ & $\mathrm{S}$ & $\mathrm{P}$ & $\mathrm{Cr}$ & $\mathrm{Ni}$ & $\mathrm{Al}$ & $\mathrm{Cu}$ \\
\hline Содержание, \% & 1,30 & 0,62 & 12,74 & 0,005 & 0,029 & 0,13 & 0,05 & 0,018 & 0,09 \\
\hline
\end{tabular}

Таблица 2. Состав, количество модификаторов и свойства образцов стали

\begin{tabular}{|c|c|c|c|c|c|}
\hline \multirow[b]{2}{*}{ Образцы } & \multicolumn{2}{|l|}{ Модификатор } & \multicolumn{3}{|c|}{ Свойства образцов стали } \\
\hline & Состав & $\begin{array}{c}\text { Содержание } \\
\text { активной } \\
\text { фазы, \% }\end{array}$ & $\begin{array}{c}\text { Временное сопротивление } \\
\text { разрыву } \sigma_{\mathrm{b}}, \mathrm{H} / \mathrm{Mm}^{2} \\
\text { (увеличение, \%) }\end{array}$ & 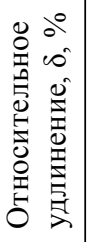 & 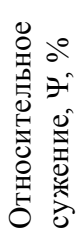 \\
\hline 1 & Углерод : медь $=1: 1$ & 0,083 & $580(5,5)$ & 10 & 13 \\
\hline 2 & Карбид бора : медь = 1:2 & 0,056 & $630(14,5)$ & 8 & 9 \\
\hline 3 & Ферротитан : медь = 1:1 & 0,083 & $590(7,3)$ & 12 & 7 \\
\hline 4 & $\begin{array}{l}\text { (Смесь карбидов вольфрама } \\
\text { и титана) : медь = 2:5 }\end{array}$ & 0,033 & $650(18,0)$ & 14 & 10 \\
\hline 5 & Карбид титана : медь = 1:1 & 0,083 & $600(9,0)$ & 10 & 12 \\
\hline 6 & $\begin{array}{l}\text { (Смесь ферротитана, карбида } \\
\text { бора, углерода) : медь = 1:4 }\end{array}$ & 0,050 & $570(3,6)$ & 8 & 16 \\
\hline 7 & Медь & 0 & 550 & 10 & 16 \\
\hline
\end{tabular}



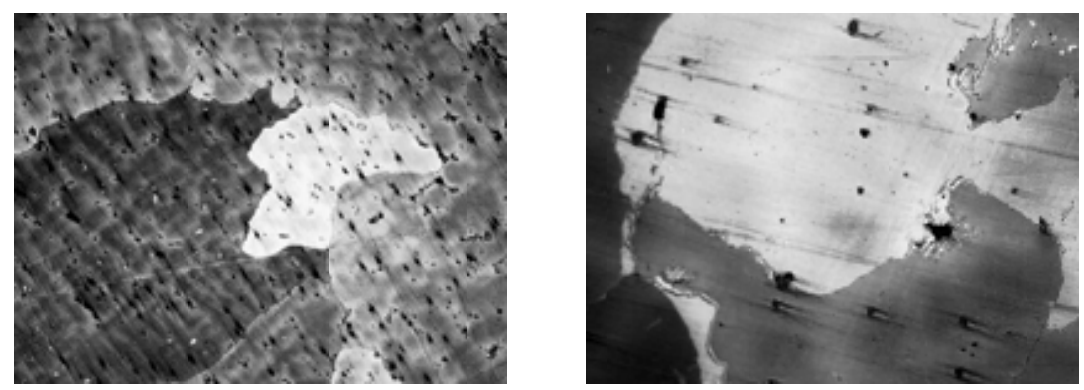

образец 1
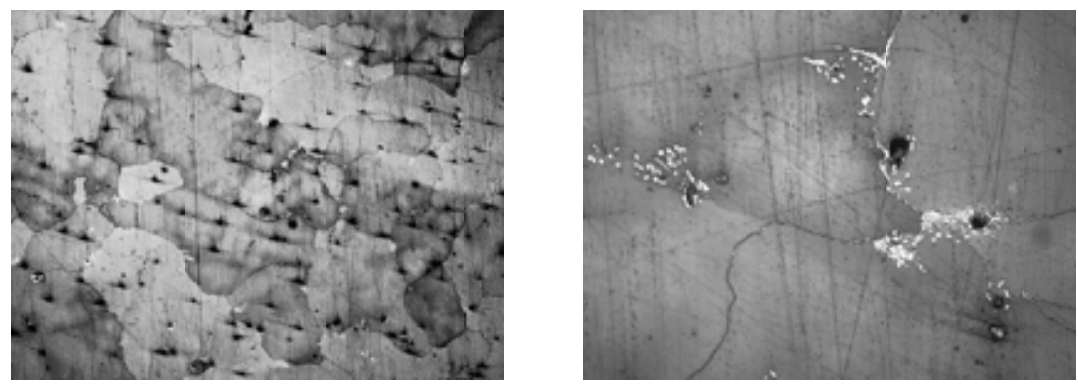

образец 2
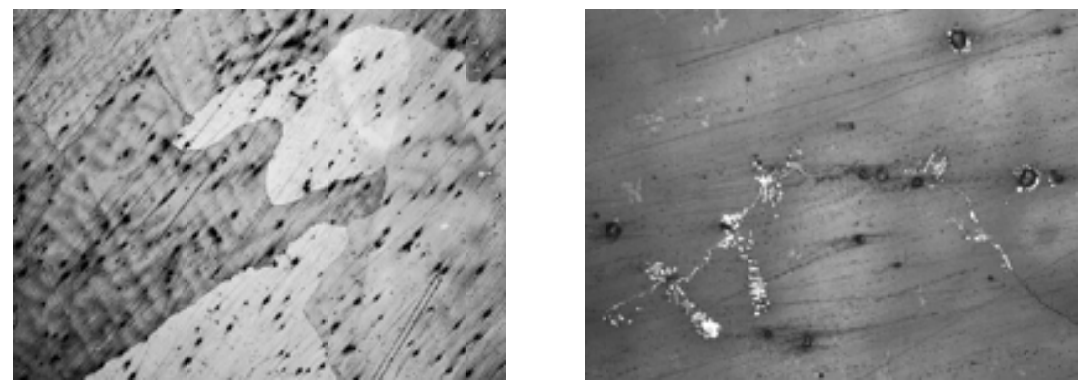

образец 3
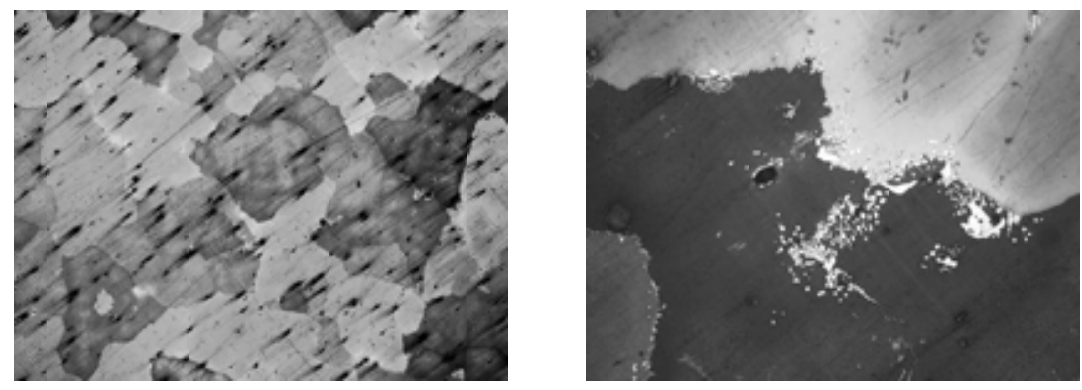

образец 4

$\times 200$

$\times 1000$

Окончание рис. 1 на с. 123 

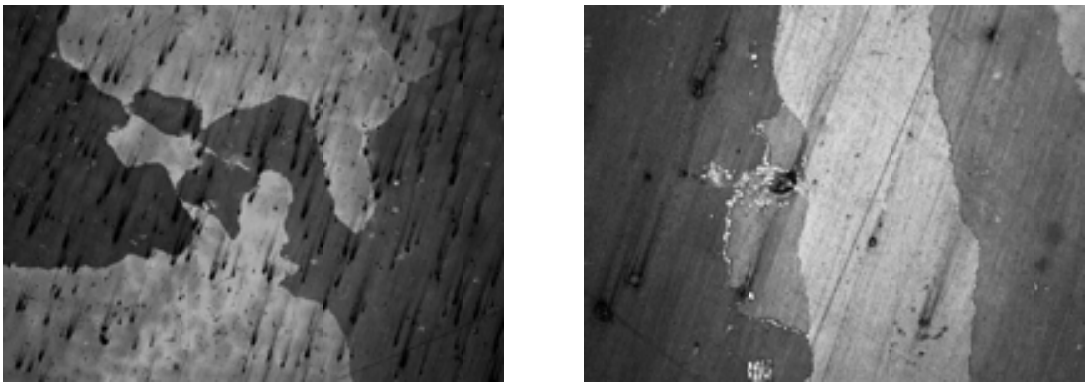

образец 5
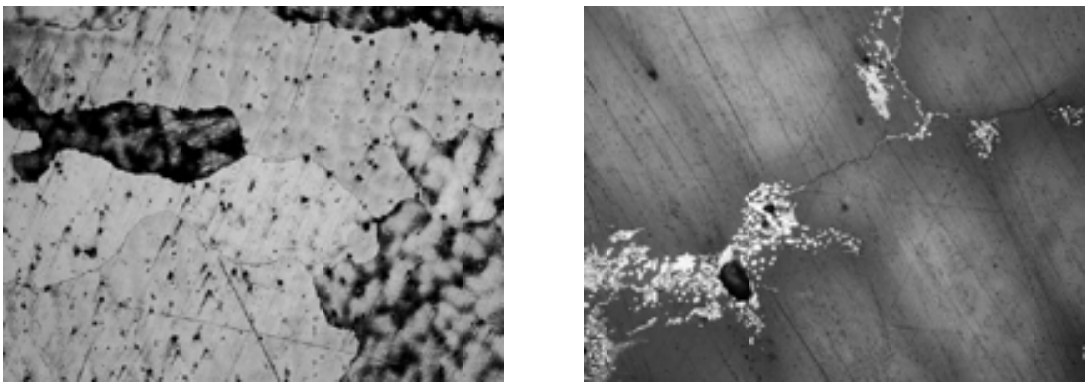

образец 6
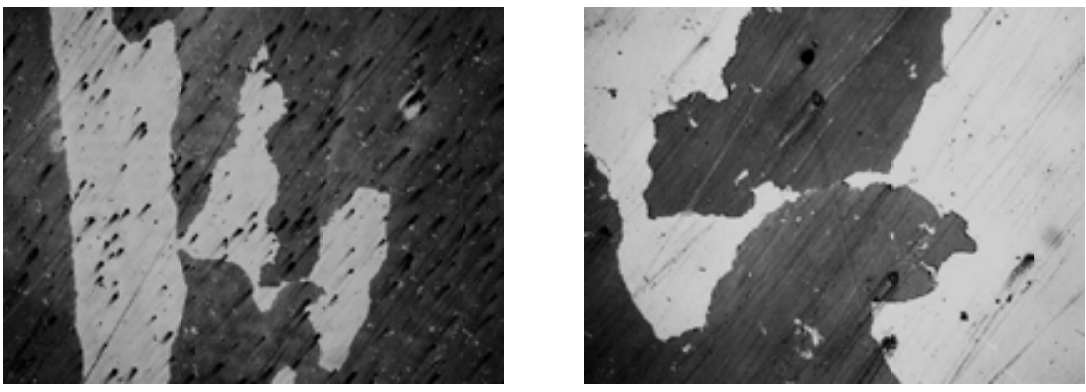

образец 7

$\times 200$

$\times 1000$

Рис. 1. Микроструктура образцов стали 110 Г13Л (травление 4\%-ным спиртовым раствором $\mathrm{HNO}_{3}$ )

Оценка величины зерна проводилась по ГОСТ 5639 (табл. 3). Видно, что в образцах 2 и 4 величина зерна соответствует двум баллам (фактический средний диаметр зерна составляет 0,387-0,694 и 0,338-0,581 мм соответственно), в остальных образцах зерно соответствует трем баллам и более (фактический средний диаметр зерна контрольного образца 2,325-3,168 мм).

\section{Заключение}

Применение дисперсных модификаторов 2 (концентрация активной фазы - карбида бора 0,056 \%) и 4 (смесь карбидов вольфрама и титана, концентрация активной фазы 0,033 \%) при внутриформенном модифицировании стали 110Г13Л способствует равномерному распределению карбидов, выделившихся внутри и по границам зерен, и значительному уменьшению размера зерна. В образцах 2 и 4 величина зерна соответствует двум баллам (фактический средний 
Таблица 3. Влияние дисперсных модификаторов на микроструктуру стали

\begin{tabular}{|c|c|c|l|}
\hline Образцы & $\begin{array}{c}\text { Величина зерна по } \\
\text { ГОСТ 5639, баллы }\end{array}$ & $\begin{array}{c}\text { Фактический } \\
\text { средний диаметр } \\
\text { зерна, мм }\end{array}$ & \multicolumn{1}{|c|}{ Распределение карбидов } \\
\hline 1 & $>3$ & $1,575-2,406$ & $\begin{array}{l}\text { Мелкие карбиды внутри } \\
\text { и по границам зерен аустенита }\end{array}$ \\
\hline 2 & 2 & $1,506-2,094$ & $\begin{array}{l}\text { Мелкие редкие выделения карбидов внутри и по } \\
\text { границам зерен аустенита }\end{array}$ \\
\hline 3 & $>3$ & $0,338-0,581$ & $\begin{array}{l}\text { Мелкие карбиды внутри и по границам зерен } \\
\text { аустенита }\end{array}$ \\
\hline 4 & $>3$ & $2,318-3,420$ & $\begin{array}{l}\text { Мелкие карбиды внутри и по границам зерен } \\
\text { аустенита }\end{array}$ \\
\hline 5 & $>3$ & $2,181-2,362$ & $\begin{array}{l}\text { Мелкие карбиды внутри и по границам зерен } \\
\text { аустенита }\end{array}$ \\
\hline 7 & $>3$ & $2,325-3,168$ & $\begin{array}{l}\text { Мелкие карбиды внутри зерен аустенита, редко } \\
\text { по границам }\end{array}$ \\
\hline
\end{tabular}

диаметр зерна 0,387-0,694 и 0,338-0,581 мм соответственно), величина зерна контрольного образца - более трех баллов (фактический средний диаметр зерна 2,325-3,168 мм).

Значительное увеличение временного сопротивления разрыву на 14,5, 18,0 и 9,0 \% показали образцы стали, отработанные модификаторами 2 (карбид бора), 4 (смесь карбидов вольфрама и титана) и 5 (карбид титана) соответственно. Кроме этого, применение модификатора 4 (смесь карбидов вольфрама и титана, концентрация активной фазы - 0,033 \%) позволило увеличить относительное удлинение на $40 \%$.

\section{Список литературы}

[1] Комушков В.П., Черепанов А.Н., Протопопов Е.В. Исследование влияния модифицирования металла нанопорошковыми материалами на качество сортовой непрерывной заготовки. Известия высших учебных заведений. Черная металлургия, 2010, 8, 57-64 [Komushkov V.P., Cherepanov A.N., Protopopov E.V. Study of the influence of modification of metal by nanopowder materials on the varietal continuous casting quality Izvestiya. Ferrous Metallurgy, 2010, 8, 57-64 (in Russian)]

[2] Предтеченский М.Р., Черепанов А.Н., Тухто О.М. и др. Плазмохимический синтез нанопорошков тугоплавких соединений и их применение для модифицирования конструкционных сталей и сплавов. Литейщик России, 2010, 3, 28-29 [Predtechenskii M.R., Cherepanov A.N., Tukhto O.M. at al. Plasmachemical synthesis of nanopowders of refractory compounds and their application for modification of structural steels and alloys, Liteishchik Rossii, 2010, 3, 28-29 (in Russian)]

[3] Комушков В.П., Черепанов А.Н., Протопопов Е.В. Модифицирование металла нанопорошковыми инокуляторами в кристаллизаторе сортовой машины непрерывного литья заготовок. Механические и металлографические исследования. Известия высших учебных заведений. Черная металлургия, 2008, 10, $21-24$ [Komushkov V.P., Cherepanov A.N., Protopopov E.V.

$$
-123-
$$


Modification of metal nanopowder inoculators in the mold of varietal continuous casting machine billet. Mechanical and metallographic tests, Izvestiya. Ferrous Metallurgy, 2008, 10, $21-24$ (in Russian)]

[4] Фейлер С.В., Черепанов А.Н., Протопопов Е.В., Калимуллин Р.Ф. Обоснование выбора инокуляторов и технологии подачи материала при модифицировании стали в процессе непрерывной разливки. Известия высших учебных заведений. Черная металлургия, 2012, 12, 64-65 [Feiler S.V., Cherepanov A.N., Protopopov E.V., Kalimullin R.F. The rationale for the selection of inoculants and the techniques of presenting the material during the treatment of steel in continuous casting process Izvestiya. Ferrous Metallurgy, 2012, 12, 64-65 (in Russian)]

[5] Крушенко Г.Г., Ямских И.С., Бонченков А.А., Мишин А.С. Повышение качества чугунных отливок с помощью нанопорошков. Металлургия машиностроения, 2002, 2(9), 20 21 [Krushenko G.G., Iamskikh I.C., Bochenkov A.A., Mishin A.S. Improving the quality of iron castings with the help of nanopowders, Metallurgy of Machinery Construction, 2002, 2(9), 20-21 (in Russian)]

[6] Пинкин В.Ф., Каренгин А.Г., Осиненко С.А. Модифицирование высокохромистого чугуна ИСЦ ультрадисперсным порошком. Литейное производство, 1994, 3, 7 [Pinkin V.F., Karengin A.G., Osinenko S.A. Modification of high-chromium cast iron COE ultrafine powder, Liteinoye proizvodstvo, 1994, 3, 7 (in Russian)]

[7] Хрычиков В.Е., Калинин В.Т., Кривошеев В.А. и др. Ультрадисперсные модификаторы для повышения качества отливок. Литейное производство, 2007, 7, 2-5 [Khrychikov V.E., Kalinin V.T., Krivosheev V.A. at al. Ultrafine modifiers to improve the quality of castings, Liteinoye proizvodstvo, 2007, 7, 2-5 (in Russian)]

[8] Jian-wei Lia, Mei-ling Chenb, Hong Gaob, Ying-hua Zhaoc Structures and Properties of Cast Irons Reinforced by Trace Addition of Modified SiC Nanopowders, Chinese journal of chemical physics, 2007, 20, 625-631.

[9] Влас М.И., Калинин В.Т., Хрычиков В.Е. и др. Модифицирование износостойких чугунов ультра- и нанодисперсными материалами. Системные технологии, 2010, 1(66), 150-162 [Vlas M.I., Kalinin V.T., Khrychikov V.E. at al. Modification of wear-resistant cast iron ultra - and nanodispersed materials, System technologies, 2010, 1(66), 150-162 (in Russian)]

[10] Protopopov E.V., Seleznev Yu.A., Cherepanov A.N. etc. Properties of Cast and Rolled Steel after Nanopowder Inoculation, External fields processing and treatment technology and preparation of nanostructure of metals and alloys, Book of the International seminar articles. Ed. by V. Gromov, 2014, 190-195.

[11] Крушенко Г.Г., Воеводина М.А. Влияние вида модификатора и фильтрования на обрабатываемость резанием чугуна с шаровидным графитом. Технология металлов, 2015, 1, 26-30 [Krushenko G.G., Voevodina M.A. The effect of the type of modifier and filtering on the machinability of nodular cast iron, Tekhnologiia metallov, 2015, 1, 26-30 (in Russian)]

[12] Комшуков В.П., Фойгт Д.Б., Черепанов А.Н., Амелин А.В. Модифицирование непрерывнолитой стали нанопорошками тугоплавких соединений. Сталь, 2009, 4, 65-68 [Komushkov V.P., Foigt D.B., Cherepanov A.N., Amelin A.V. Modification of continuously cast steel nanopowders of refractory compounds, Stal', 2009, 4, 65-68 (in Russian)]

[13] Lamei C., Guangxun L., Huaipeng G. etc. Modification of the Structure and Properties of Heat-Resistant Alloys with the Help of Nanopowders of Refractory, Compounds, International 
Conference on Manipulation, Manufacturing and Measurement on the Nanoscale, 3M-NANO 2012, Conference Proceedings, 2012, 385-388.

[14] Полубояров В.А., Коротаева 3.А., Жданок А.А. Внутриформенное модифицирование серого чугуна. Влияние состава и концентрации наноразмерных модификаторов на процессы кристаллизации и эксплуатационные характеристики. Сборник докладов пятого международного конгресса «Цветные металльl», Красноярск, 2013, 490-495 [Poluboiarov V.A., Korotaeva Z.A., Zhdanok A.A. Form modification of cast iron. The influence of composition and concentration of nano-modifiers on the crystallization processes and performance, 5 international Congress "Nonferrous metals", ed. by G.L. Pashkov, P.V. Polyakov, September 4-6, , Krasnoyarsk, 2013, 490495 (in Russian)]

[15] Полубояров В.А., Коротаева 3.А., Жданок А.А. Внутриформенное модифицирование серого чугуна. Влияние наноразмерных модификаторов, полученных плазмохимическим и СВС-методами, на процессы кристаллизации и эксплуатационные характеристики. Сборник докладов пятого международного конгресса «Цветные металль», Красноярск, 2013 [Poluboiarov V.A., Korotaeva Z.A., Zhdanok A.A. Form modification of cast iron. The influence of nanosized modifier obtained by plasma and SVS methods, crystallization processes and performance, 5 international Congress "Nonferrous metals", ed. by G.L. Pashkov, P.V. Polyakov, September 4-6, Krasnoyarsk, 2013, 486-490 (in Russian)]

[16] Полубояров В.А., Коротаева 3.А., Жданок А.А. Внутриформенное модифицирование серого чугуна. Влияние наноразмерных модификаторов на основе карбида кремния на процессы кристаллизации и эксплуатационные характеристики. Сборник докладов пятого международного конгресса «Цветные металльl», Красноярск, 2013 [Poluboiarov V.A., Korotaeva Z.A., Zhdanok A.A. Form modification of cast iron. The influence of nano-modifiers on the basis of carbide of silicon on the crystallization processes and performance, 5 international Congress "Nonferrous metals", ed. by G.L. Pashkov, P.V. Polyakov, September 4-6, Krasnoyarsk, 2013, 481-486 (in Russian)]

[17] Полубояров В.А., Жданок А.А., Коротаева 3.А., Кузнецов В.А. Получение WC и $\mathrm{W}_{2} \mathrm{C}$ в системе W-TI-C методом самораспространяющегося высокотемпературного синтеза. Неорганические материаль, 2014, 50(5), 1-4 [Poluboiarov V.A., Zhdanok A.A., Korotaeva Z.A., Kuznetsov V.A. The receipt of WC and $\mathrm{W} 2 \mathrm{C}$ in $\mathrm{W}-\mathrm{TI}-\mathrm{C}$ propagating high-temperature synthesis, Neorganicheskie materialy, 2014, 50(5), 1-4 (in Russian)]. DOI: 10.7868/S0002337X14050157. 